\title{
Study on fatigue crack nucleation of electrodeposited nanocrystalline nickel
}

\author{
Jijia Xie ${ }^{\mathrm{a}}$, Xiaolei $\mathrm{Wu}^{\mathrm{b}}$, Youshi Hong ${ }^{\mathrm{c}}$ \\ State Key Laboratory of Nonlinear Mechanics, Institute of Mechanics \\ Chinese Academy of Sciences, Beijing, 100080, China \\ axiejj@Inm.imech.ac.cn, ${ }^{b} x \mid w u @ i m e c h . a c . c n,{ }^{c h o n g y s @ i m e c h . a c . c n ~}$
}

Keywords: Nanocrystalline; fatigue crack nucleation; Nickel; Atomic Force Microscopy; roughness

\begin{abstract}
The mechanism of fatigue crack nucleation for nanocrystalline (nc) nickel was experimentally investigated in this paper. The samples of electrodeposited nc nickel were loaded cyclically by using a three point bending instrument at first. Then, atomic force microscopy (AFM) was used to scanning the sample surface after fatigue testing. The results indicated that, after fatigue testing, there are vortex-like cells with an average size of $108 \mathrm{~nm}$ appeared along the crack on nc nickel sample. And, the roughness of sample surface increased with the maximum stress at the surface.
\end{abstract}

\section{Introduction}

The electrodeposited nanocrystalline (nc) metal is often used as a model material in investigations due to its full density and quasi equilibrium microstructure [1-4]. The mechanical properties, such as tension, creep, and indentation, were reported to study the deformation mechanism of nc metals. But, as mentioned in Kumar et al's review [5], electrodeposition typically yield only thin foils that are at most several hundred micrometers in thickness. This aroused experimental difficulties in fatigue testing. Hanlon et al $[6,7]$ investigated the fatigue properties of nc and ufg electrodeposited Ni. Their experimental results indicated that, with grain refinement, the resistance to failure under stress-controlled fatigue increased. Moser et al [8] observed cyclic strain hardening and frequency-dependent fatigue life in electrodeposited nc Ni. However at present, the mechanism of fatigue crack nucleation for nc materials is not very clear. In relation with coarse grain cases, where persistent slip bands (PSBs) were observed on the sample surface while cyclic loading, several models based on dislocation interaction were proposed to predict the fatigue life [9]. But, with the grain size down to nanometer regime, the pile up of dislocations becomes more difficult, and other mechanism such as grain boundary sliding or Coble creep may replace the dislocation mechanism as the main deformation mechanism [10-17]. Obviously, the performance of fatigue crack nucleation may vary due to the change of deformation mechanism.

The aim of this paper is to study the mechanism of fatigue crack initiation experimentally. First, fatigue testing was carried out with the nc and coarse-grained (cg) Nickel samples. Then, the sample surface was observed because that the fatigue cracks often initiate from there. For the very fine size of microstructure of nc materials, atomic force microscopy (AFM) was used in this investigation to observe the sample surface before and after fatigue loading.

\section{Materials and experimental method}

Electrodeposited nc Ni sheets with $120 \mu \mathrm{m}$ in thickness were used in this paper. The average grain size of $26 \mathrm{~nm}$ was measured by image analysis from TEM photos. On the other hand, a cg Ni sheet with $42 \mu \mathrm{m}$ average grain size was used as a comparison with the $\mathrm{nc} \mathrm{Ni}$.

Fatigue experiments for the nc and cg Ni sheets were conducted using a three point bending grip with a span of $10 \mathrm{~mm}$. The rectangular specimen was $15 \mathrm{~mm}$ long, $5 \mathrm{~mm}$ wide and $120 \mu \mathrm{m}$ thick. Before the testing, specimens were ground and polished. Fatigue loading was applied by a rotation machine at room temperature. Fig.1(a) is the schematic drawing of the machine and the grip. When 
the shaft rotated, the cam will push the lower grip up and back. Then, the lower surface of the specimen was engaged the tension fatigue load. The maximum load at the sample surface is controlled by the end deflection of the sample. The cyclic frequency is $52.5 \mathrm{~Hz}$. The waveform is sinusoidal.

After cyclically loading on samples to fracture, optical microscopy (OM) and AFM were used to observe the crack nucleation and measure the surface roughness. Fig.1(b) shows the schematic drawing of the positions observed by OM/AFM.
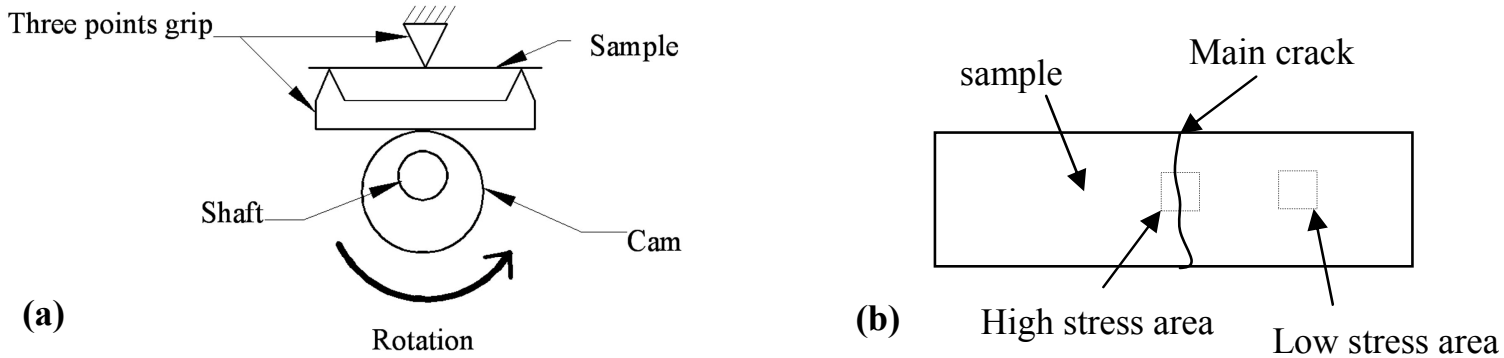

Fig.1 Schematic drawing of (a) fatigue testing system and (b) positions observed by OM/AFM
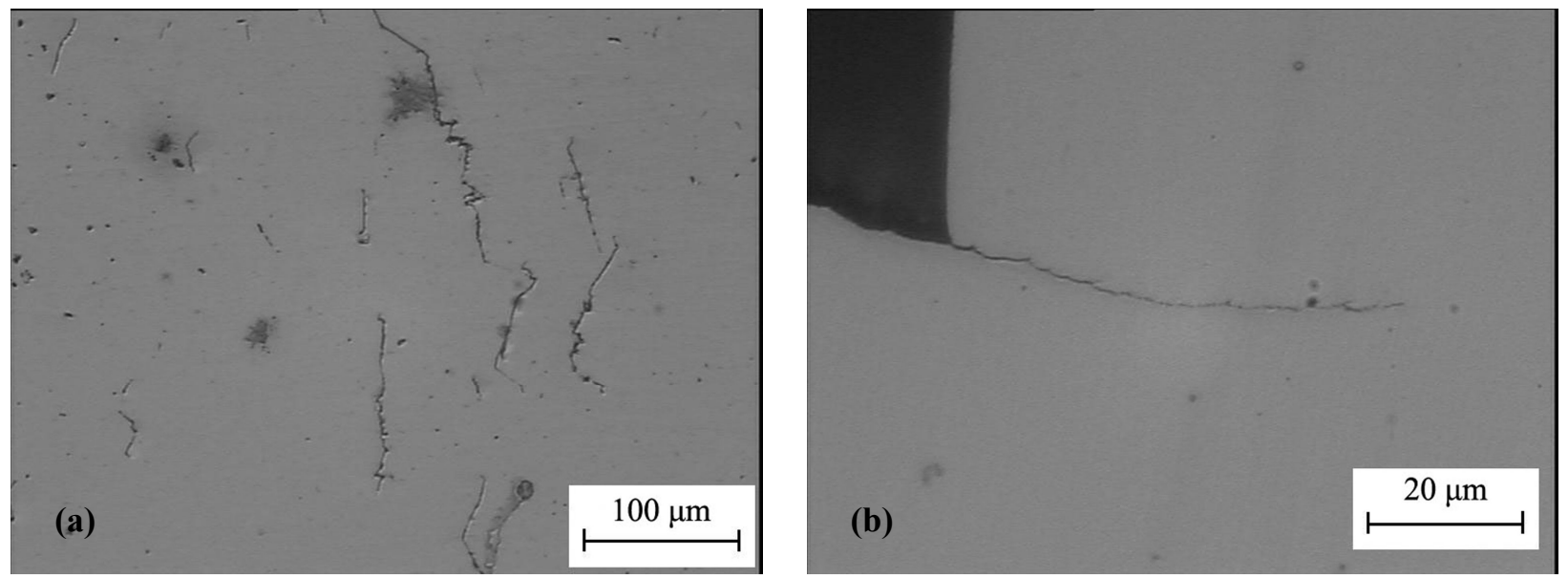

Fig.2 Optical photographs of sample surface after fatigue testing (a) CG Ni sample after $2 \times 10^{6}$ cycles of loading. (b)NC Ni after $10^{5}$ cycles of loading.

\section{Results}

The sample surface shown in Fig.1(b) was observed by OM periodically in the fatigue testing. As shown in Fig.2(a), after several millions of loading cycles, there are plenty of short cracks appear in the surface of samples. This indicates that the crack nucleation of $\mathrm{cg} \mathrm{Ni}$ is of a collective mode namely a group of cracks prevailing. Whereas for $\mathrm{nc} \mathrm{Ni}$, as shown in Fig.2(b), there is only one crack in the fatigue process.

After fatigue testing, AFM was used to scan the sample surface along the crack. As shown in Fig.3(a), there are vortex-like cells appear near the crack in $\mathrm{nc} \mathrm{Ni}$, which was more obvious in Fig.3(b) and Fig.3(c). The size of this kind of cells was analyzed by using image analysis software. Fig.3(e) gives the histogram of the cell diameter. The average value is $108 \mathrm{~nm}$. Fig.3 (d) shows the section lines of the scanning area. It is seen that the height of the vortex-like cells is about $10 \mathrm{~nm}$. It is different with the sample surface before the fatigue testing.

There are no any vortex-like cells observed on the other area, even in the high stress area. However, for $\mathrm{nc} \mathrm{Ni}$, the roughness of the high stress area is large than that of the low stress area. For cg Ni, it looks that the roughness does not change with the applied stress. Table 1 lists the roughness measured by using AFM. This can also be observed in Fig.4. 


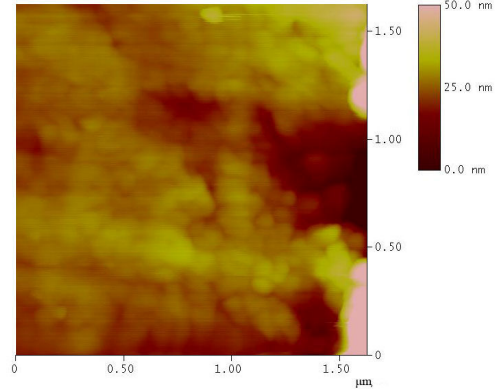

(a)

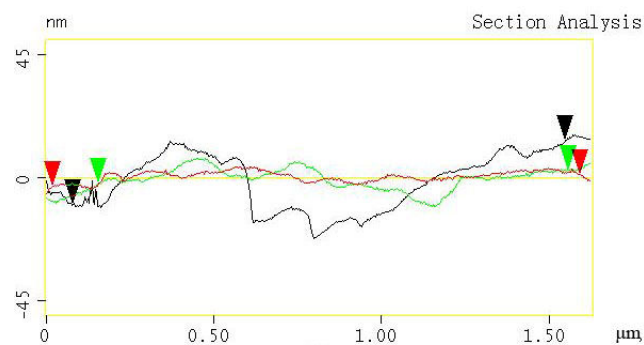

(d)

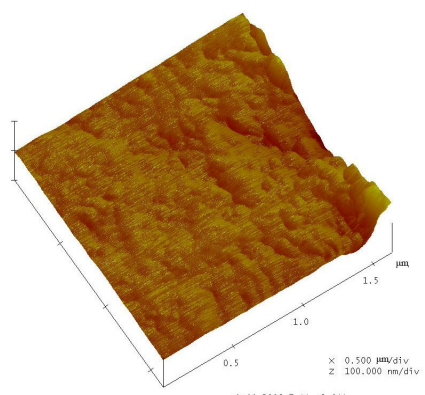

(b)

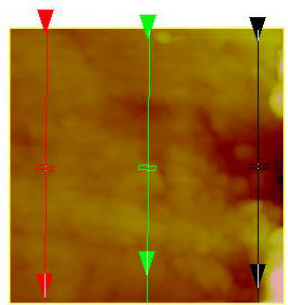

m.

$$
\text { (e) }
$$

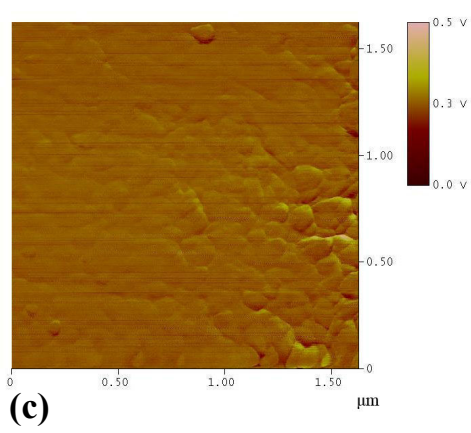

(c)

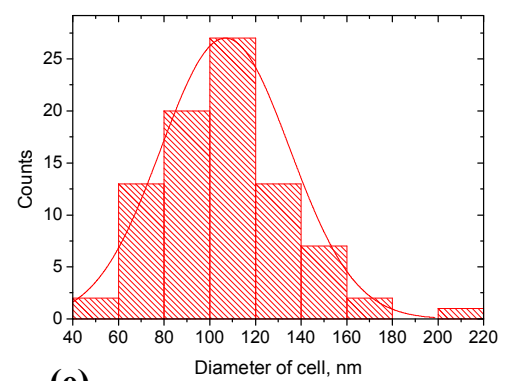

e)

Fig.3 (a) Height map of the scanning area near the crack on the sample surface. (b) 3-D map of the scanning area (c) Friction map of the scanning area (d) Section map of the scanning area (e) Histogram of the cell diameter, which was measured by using image analysis. The average value of the cell diameter is $108 \mathrm{~nm}$. Scanning range: $1.6 \mu \mathrm{m} \times 1.6 \mu \mathrm{m}$

Table 1 Roughness of the scanning area for nc Ni and cg Ni.

\begin{tabular}{|c|c|c|c|c|}
\hline Scanning area & $\mathrm{Nc} \mathrm{Ni}$ & $\mathrm{Ra}[\mathrm{nm}]$ & $\mathrm{Cg} \mathrm{Ni}$ & $\mathrm{Ra}[\mathrm{nm}]$ \\
\hline High stress area & \multicolumn{2}{|c|}{2.61} & \multicolumn{2}{|c|}{1.19} \\
\hline Low stress area & & & & \\
\hline
\end{tabular}
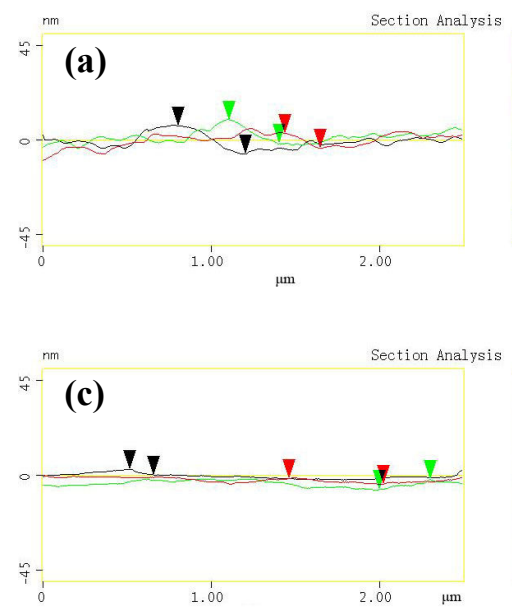
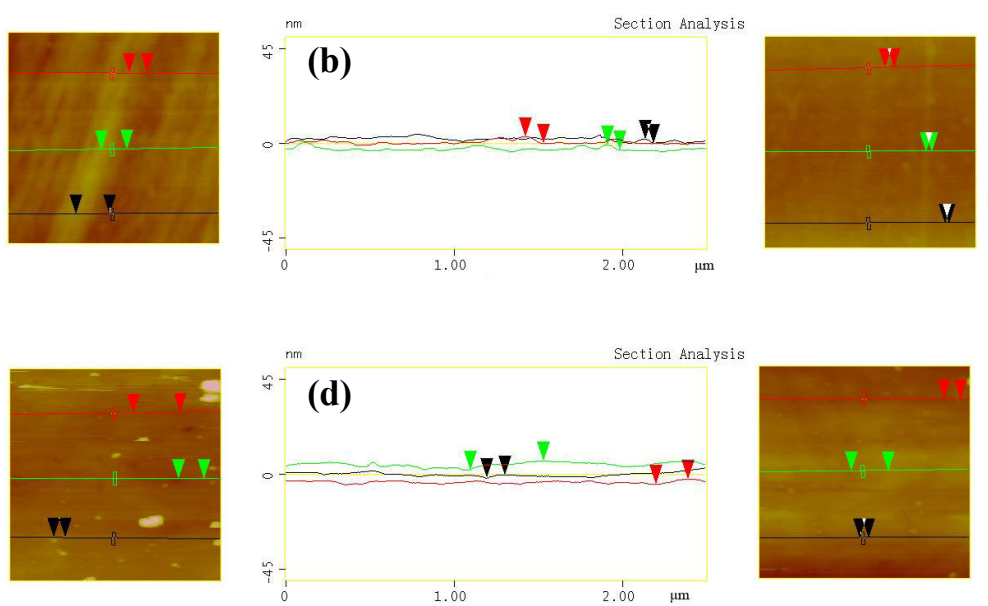

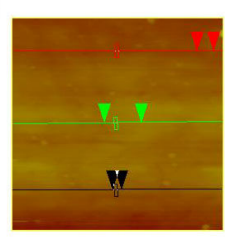

Fig.4 Section lines of different area. (a) High stress area of nc Ni (b) Low stress area of nc Ni (c) High stress area of cg Ni (d) Low stress area of cg Ni. Scanning range: $2.5 \mu \mathrm{m} \times 2.5 \mu \mathrm{m}$ 


\section{Discussion}

The AFM map indicated that, after fatigue testing, there are vortex-like cells with an average size of $108 \mathrm{~nm}$ appeared along the crack on nc Ni sample. It is larger than the average grain size of nc Ni. And, the roughness of sample surface increased with the maximum stress at the surface. This suggests that the crack nucleation mechanism of $\mathrm{nc} \mathrm{Ni}$ is related with the deformation of grain clusters. The movement of grain clusters under cyclic loading leads to the rough sample surface and the formation of a small valley. With the surface roughness increased the depth of valleys increased to form the main crack.

Wang et al [11] studied the static and dynamic creep behavior of the electrodeposited nc $\mathrm{Ni}$ at the room temperature. It appeared that grain boundary sliding and diffusive matter transport played an important role in terms of deformation mechanisms of nc materials. Yagi et al [12] and Chinh et al [13] provided some experimental evidence for grain boundary sliding in nc or ultrafine-grained metals. Their observations were very similar with the results in this investigation. Based on these experimental results, a model based on grain boundary sliding was proposed to predict the fatigue life of nc materials.

(a)

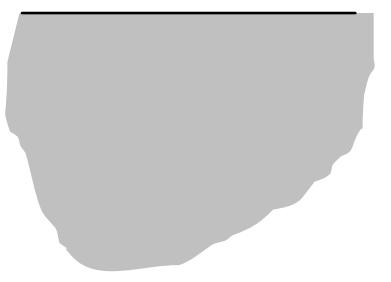

(b)

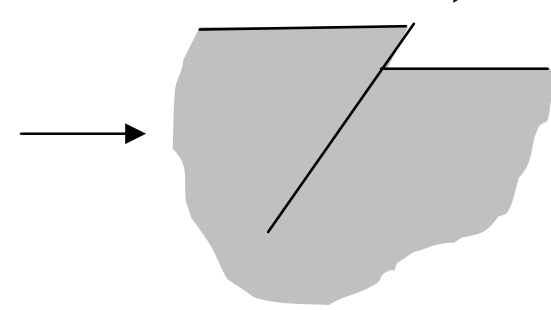

(c)

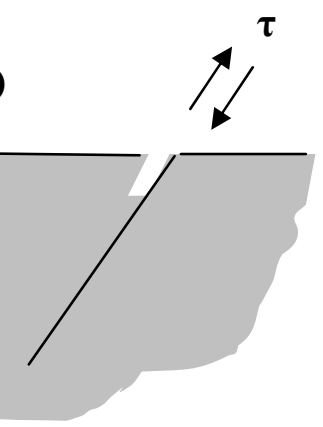

Fig.5 Schematic illustration of fatigue crack initiation mechanism for nc Ni. (a) Sample as received (b) After a cycle of loading, parts of sample slip along the shear plane and a step forms at surface. (c) After another cycle of loading, parts of sample slip along adjacent shear plane and a valley forms at surface.

As shown in Fig.5, after one cycle of loading, parts of sample will slip along the shear plane. This induces a step formed at the sample surface. After another load cycle, for the reason of surface oxidation or pollution, sample will slip along another shear plane. If this plane is close with the first plane, then a valley will formed. These kinds of valley will become deeper with the increase of the load cycles. At last, one of such kind of valleys will grow up to a main crack.

An expression for the grain boundary sliding rate was given by Raj and Ashby [17]. At temperatures significantly below $\theta \mathrm{m} / 2$,

$$
\dot{u}=\frac{2 \delta \Omega D_{\mathrm{B}} \tau_{\mathrm{a}}}{k \theta} \frac{1}{h^{2}},
$$

where the parameter $\mathrm{h}$ is the amplitude of the sinusoidal grain boundary, which is taken as $\mathrm{d} / 4$. In this investigation, $\mathrm{d}$ is the average size of the vortex like cells. $\Omega$ is the atomic volume. $\delta$ is the thickness of the boundary. $\theta$ is the temperature. $\tau$ a is the shear stress acted on the grain boundary. In the fatigue testing, it can be expressed as follow.

$$
\tau_{a}=\frac{\sigma_{\mathrm{m}}+\sigma_{\mathrm{a}} \cos (\omega t)}{2},
$$

where $\sigma \mathrm{m}$ is the average stress. $\sigma \mathrm{a}$ is the amplitude of the stress wave. $\omega$ is the frequency of the stress wave. Insert Eq. 2 into Eq.1, we get 


$$
\dot{u}=\frac{16 \delta \Omega D_{\mathrm{B}}}{k \theta} \frac{1}{d^{2}}\left(\sigma_{\mathrm{m}}+\sigma_{\mathrm{a}} \cos (\omega t)\right)
$$

The height of the surface step formed by grain boundary sliding after one cycle of loading can be expressed as follow.

$$
H=\frac{1}{\sqrt{2}} \int_{0}^{T} \dot{u} \mathrm{~d} t=\frac{16 \delta \Omega D_{\mathrm{B}} \sigma_{\mathrm{m}}}{\sqrt{2} k \theta} \frac{1}{d^{2}} T
$$

The valleys depth increase with the cycles of loading. It will become short cracks on the sample surface. Suresh \& Ritchie [9] suggested four definitions for short cracks. One of them is called mechanically small flaws. The near tip plasticity is comparable to the crack size for this type of short crack. The transition crack size from the mechanical short crack to long crack was proposed by Kitagawa \& Takahashi [9].

$$
a_{0}=\frac{1}{\pi}\left(\frac{\Delta K_{\mathrm{th}}}{\Delta \sigma_{\mathrm{e}}}\right)^{2},
$$

where the parameter $\Delta K_{\text {th }}$ is the threshold stress intensity factor range. $\Delta \sigma_{\mathrm{e}}$ is the smooth sample fatigue limit. When the short crack size reaches the transition crack size, the crack initiation should be finished. Then, the cycles for fatigue crack initiation can be estimated as following.

$$
N=2 A \frac{a_{0}}{H},
$$

where parameter A is the probability for the slipping at the same location on the sample surface. This model indicates that the fatigue life is related with the average stress, the frequency of loading, temperature, etc. For the complexity of the fatigue crack nucleation, more experimental investigations should be proposed to validate this model.

Other than the crack nucleation mechanism of $\mathrm{nc} \mathrm{Ni}$, the crack nucleation for $\mathrm{cg} \mathrm{Ni}$ is of traditional PSB mechanism. With the cycles of load increased, the dislocations moved in the persistent slip bands, which induced the short cracks initiation in some grains. The propagations of these short cracks will be interrupted by the grain boundary. That means there will have a group of short cracks appeared at the sample surface before a main crack formed. This is the reason why the crack nucleation of cg $\mathrm{Ni}$ is of a collective mode. However, for $\mathrm{nc} \mathrm{Ni}$, the crak nucleation mechanism might be related with the grain boundary sliding. The grain boundary will not be the obstacle for the propagation of small valley formed by the movement of grain clusters. That's why there are only one crack observed on the sample surface for nc Ni.

\section{Concluding remarks}

The crack nucleation of $\mathrm{cg} \mathrm{Ni}$ is of a collective mode namely a group of cracks prevailing, whereas for nc Ni there is only one crack in the fatigue process.

After fatigue testing, there are vortex-like cells with an average size of $108 \mathrm{~nm}$ appeared along the crack on nc Ni sample. And, the roughness of sample surface increased with the maximum stress at the surface. This suggests that the crack nucleation of $\mathrm{nc} \mathrm{Ni}$ is related with the deformation of grain clusters.

A model based on grain boundary sliding mechanism was proposed for nc $\mathrm{Ni}$ fatigue crack nucleation.

\section{Acknowledgements}

This work was supported by National Natural Science Foundation of China $(10472117,50571110)$ 


\section{References}

[1] Kh. Saber, C.C. Koch, P.S. Fedkiw: Materials Science and Engineeering A, 341( 2003), p. 174-181

[2] U. Erb: Nanostruct Mater, 6 (1995), p. 533-538

[3] Y.F. Shen, L. Lu, Q.H. Lu, Z.H. Jin, K. Lu: Scripta Materilia, 52 (2005), p. 989-994

[4] L. Lu, R. Shwaiger, Z.W. Shan, M. Dao, K. Lu, S. Suresh: Acta Materilia, Vol.53 No.7 (2005), p. 2169-2179

[5] K.S. Kumar, H.Van Swygenhoven, S. Suresh: Acta Materialia 51(2003), p. 5743-5774

[6] T. Hanlon, Y.-N. Kwon, S. Suresh: Scripta Materialia 49( 2003), p. 675-680

[7] T. Hanlon, E.D. Tabachnikova, S. Suresh: Int. Journal of Fatigue 27( 2005), p.1147-1158

[8] B. Moser, T. Hanlon, K.S. Kumar, S. Suresh: Scripta Materialia, 54 (2006), p. 1151-1155

[9] S. Suresh: Fatigue of materials (Cambridge University Press, 1991).

[10]M.F. Ashby: Acta Metallurgica, 20 (1972), p. 887-897

[11]Ning Wang, Zhirui Wang, K.T. Aust and U. Erb: Materials Science and Engineering A, Vol.237 No.2 (1997), p. 150-158

[12]N. Yagi, A. Rikukawa, H. Mizubayashi, H. Tanimoto: Materials Science and Engineering A, Vol.442 No.1-2 (2006), p. 323-327

[13]Nguyen Q. Chinh, Peter Szommer, Zenji Horita, Terence G. Langdon: advanced materials, 18 (2006), p. 34-39

[14] W.M. Yin, S.H. Whang, R. Mirshams, C.H. Xiao: Materials Science and Engineering A, 301 (2001), p.18-22

[15] W.M. Yin and S.H. Whang: Scripta materialia, 44 (2001), p. 569-574

[16] W.M. Yin, S.H. Whang, R.A. Mirshams: Acta Materialia, 53 (2005), p. 383-392

[17]M.A. Meyers, A. Mishra, D.J. Benson: Progress in Materials Science 51 (2006), p. 427-556 


\section{Advances in Fracture and Materials Behavior}

10.4028/www.scientific.net/AMR.33-37

\section{Study on Fatigue Crack Nucleation of Electrodeposited Nanocrystalline Nickel}

10.4028/www.scientific.net/AMR.33-37.925

\section{DOI References}

[1] Kh. Saber, C.C. Koch, P.S. Fedkiw: Materials Science and Engineeering A, 341( 2003), p. 174-181

doi:10.1016/S0921-5093(02)00198-3

[2] U. Erb: Nanostruct Mater, 6 (1995), p. 533-538

doi:10.1016/0965-9773(95)00114-X

[3] Y.F. Shen, L. Lu, Q.H. Lu, Z.H. Jin, K. Lu: Scripta Materilia, 52 (2005), p. 989-994

doi:10.1016/j.scriptamat.2005.01.033

[4] L. Lu, R. Shwaiger, Z.W. Shan, M. Dao, K. Lu, S. Suresh: Acta Materilia, Vol.53 No.7 (2005), p. 21692179

doi:10.1016/j.actamat.2005.01.031

[6] T. Hanlon, Y.N. Kwon, S. Suresh: Scripta Materialia 49( 2003), p. 675-680

doi:10.1016/S1359-6462(03)00407-X

[7] T. Hanlon, E.D. Tabachnikova, S. Suresh: Int. Journal of Fatigue 27( 2005), p.1147-1158

doi:10.1016/j.ijfatigue.2005.06.036

[8] B. Moser, T. Hanlon, K.S. Kumar, S. Suresh: Scripta Materialia, 54 (2006), p. 1151-1155

doi:10.1016/j.scriptamat.2005.11.054

[10] M.F. Ashby: Acta Metallurgica, 20 (1972), p. 887-897

doi:10.1016/0001-6160(72)90082-X

[11] Ning Wang, Zhirui Wang, K.T. Aust and U. Erb: Materials Science and Engineering A, Vol.237 No.2 (1997), p. 150-158

doi:10.1016/S0965-9773(97)90066-0

[12] N. Yagi, A. Rikukawa, H. Mizubayashi, H. Tanimoto: Materials Science and Engineering A, Vol.442

No.1-2 (2006), p. 323-327

doi:10.4028/www.scientific.net/KEM.319.133

[13] Nguyen Q. Chinh, Peter Szommer, Zenji Horita, Terence G. Langdon: advanced materials, 18 (2006), p. 34-39

doi:10.1016/j.msea.2006.07.014

[14] W.M. Yin, S.H. Whang, R. Mirshams, C.H. Xiao: Materials Science and Engineering A, 301 (2001), p.18-22

doi:10.1016/S0921-5093(01)01213-8

[15] W.M. Yin and S.H. Whang: Scripta materialia, 44 (2001), p. 569574

doi:10.1016/S1359-6462(00)00639-4

[16] W.M. Yin, S.H. Whang, R.A. Mirshams: Acta Materialia, 53 (2005), p. 383392

doi:10.1016/j.actamat.2004.09.034

[17] M.A. Meyers, A. Mishra, D.J. Benson: Progress in Materials Science 51 (2006), p. 427-556

doi:10.1007/s11837-006-0214-6 